\title{
Prevalence of the metabolic syndrome in Chinese adolescents
}

\author{
Y. Li ${ }^{1,2}$, X. Yang ${ }^{1}$, F. Zhai ${ }^{1}$, F. J. Kok ${ }^{2}$, W. Zhao ${ }^{1}$, J. Piao ${ }^{1}$, J. Zhang ${ }^{1}$, Z. Cui ${ }^{1}$ and G. Ma ${ }^{1,2 *}$ \\ ${ }^{1}$ National Institute for Nutrition and Food Safety, Chinese Center for Disease Control and Prevention, 29 Nan Wei Road, \\ Beijing 100050, China \\ ${ }^{2}$ Division of Human Nutrition, Wageningen University, The Netherlands
}

(Received 8 February 2007 - Revised 9 May 2007 - Accepted 15 June 2007)

Since national figures on the occurrence of metabolic syndrome among Chinese adolescents are lacking, this study aims to estimate its prevalence and distribution among Chinese youngsters. The 2002 China National Nutrition and Health Survey is a nationally representative cross-sectional study. Applying the criteria for US adolescents, we estimated the prevalence of metabolic syndrome among 2761 adolescents aged 15 to 19 years. The prevalence of metabolic syndrome among Chinese adolescents overall was $3.7 \%$ (10\% in US adolescents). It was $35.2 \%, 23.4 \%$ and $2.3 \%$ among adolescents who were overweight (BMI $\geq 95$ th percentile), at risk of overweight (BMI between 85th and 95th percentile) and normal weight (BMI below the 85th percentile), respectively. Urban boys had the highest rate $(5.8 \%)$ compared with girls and rural youngsters. Among adolescents who had a BMI $\geq 85$ th percentile and one or two parent(s) with metabolic syndrome, the prevalence was $46.4 \%$. A total of $96 \%$ of overweight adolescents had at least one and $74.1 \%$ overweight adolescents had at least two abnormalities of metabolic syndrome. Based on these figures, it is estimated that more than three million Chinese adolescents have metabolic syndrome. Both overweight and metabolic syndrome prevalence among adolescents are still relatively low in China, but the prevalence of metabolic syndrome among Chinese overweight adolescents is similar to those living in the USA.

Metabolic syndrome: Adolescent: Overweight: Obesity

Metabolic syndrome refers to a clustering of specific CVD risk factors ${ }^{1}$. There are several definitions of metabolic syndrome for adults ${ }^{2-7}$, such as the International Diabetes Federation definition $^{4}$, WHO criteria $^{7}$ and the Third Report of the National Cholesterol Education Program's Adult Treatment Panel (ATP III) criteria ${ }^{2}$. Paediatric metabolic syndrome has been reported in many populations, but the estimations are difficult to compare because a unanimous definition is lacking $^{8-13}$. Based on the ATP III criteria, Cook et al. ${ }^{14}$ proposed paediatric metabolic syndrome criteria for US children and adolescents defined as having three or more of the following abnormalities: high TAG level; low HDL-cholesterol level; high fasting glucose level; abdominal obesity; hypertension. In 2004, de Ferranti et al. ${ }^{15}$ developed less restrictive criteria analogous to ATP III. According to de Ferranti's definition, the prevalence of metabolic syndrome among US adolescents was $10 \%$ and nearly $30 \%$ among overweight/obese US adolescents ${ }^{15}$.

In China, paediatric overweight and obesity emerged only during the last few decades. Being very low in the $1980 \mathrm{~s}$, the overall prevalence of overweight and obesity among children in China were approximately $5 \%$ and $2 \%$, respectively, in $2002^{16}$. Along with the rise of childhood obesity, related metabolic abnormalities began to be routinely observed and reported $^{8-13,15}$. But no national representative data about metabolic syndrome of Chinese adolescents have been published.
The purpose of the current study is to estimate the prevalence and distribution of metabolic syndrome among Chinese adolescents using the national representative survey data of the 2002 China National Nutrition and Health Survey.

\section{Subjects and methods}

\section{Sampling}

The 2002 China National Nutrition and Health Survey is a nationally representative cross-sectional survey that covered thirty-one provinces, autonomous regions and the municipalities directly affiliated to the central government (Hong Kong, Macao and Taiwan were not included). Detailed information of the sampling method has been described elsewhere ${ }^{17}$. Briefly, a multi-step cluster sampling method was used for subject selection. A total of 272023 subjects aged 2-101 years old representative for the Chinese population were surveyed. The sample consisted of 8456 adolescents aged 15-19 years old and one third of the selected families ( $n$ 2913) were randomly selected to have blood samples drawn.

Among the 2913 adolescents, missing values for height/ weight, waist, blood pressure and blood samples accounted for $1.8 \%, 0.8 \%, 2.1 \%$ and $2.1 \%$, respectively. A total of 2761 adolescents had complete measurements of waist circumference, blood pressure, plasma glucose, TAG, HDL 
and were not currently pregnant. Children younger than 15 years were recruited, but did not have waist circumference and blood pressure measurements taken. There was no significant difference in age, weight, height, BMI and sex ratio between adolescents who had complete measurements and those who did not.

Among the 2761 subjects, 2469 adolescents' mothers (response $89.4 \%$ ) and 2186 adolescents' fathers (response $79.2 \%$ ) participated in the investigation, 2326 mothers (response 94.2\%) and 2064 fathers (response 94.4\%) had complete measurements for metabolic syndrome. Of them, 1861 adolescents had full information of both mother and father. There was no significant difference in weight, height and BMI between parents who had complete measurements and those who did not. Parents who completed the measurements were 0.4 years older than those who did not.

\section{Measurements}

The fasting body weight, height, waist circumference and blood pressure of the adolescents and their (biological) parents were measured following standardized procedures by trained interviewers. The waist circumference was measured to the nearest $0 \cdot 1 \mathrm{~cm}$ at the midpoint between the bottom of the rib cage and the top of the iliac crest at the end of exhalation ${ }^{18}$. Subjects' seated resting blood pressure was measured twice to the nearest $2 \mathrm{mmHg}$. The first and fifth Korotkoff sounds were used to represent the systolic and diastolic blood pressure ${ }^{18}$. The mean of these two measurements was recorded.

Fasting blood samples $(5 \mathrm{ml})$ of the adolescents and their (biological) parents were collected after approximately 10$14 \mathrm{~h}$ overnight fast, drawn into tubes containing heparin as an anticoagulant for preparation of plasma. After the blood was drawn, the tubes were gently shaken and then separated by centrifugation at $3200 \mathrm{rpm}$ for $10-15 \mathrm{~min}$. Plasma glucose level was measured with a spectrophotometer within $4 \mathrm{~h}$ after a fasting blood sample was obtained. Other plasma samples were moved into airtight storage tubes and stored at $-80^{\circ} \mathrm{C}$ prior to shipment on dry ice to the Chinese Center for Disease Control and Prevention for lipid measurements. Plasma total cholesterol, TAG and HDL-cholesterol were measured enzymatically with a Hitachi 7060, 7180 auto-analyzer (Hitachi, Tokyo, Japan) $^{18}$.

The protocol of the survey was approved by the Ethical Committee of the National Institute for Nutrition and Food Safety, Chinese Center for Disease Control and Prevention. Signed consent forms were obtained from both their parents or guardians and the adolescents themselves.

\section{Quality control of physical measurements}

Fasting body weight, height and blood pressure were all objectively measured by trained investigators and the duplicate measurements in subgroups showed very high reproducibility (correlation coefficients of duplicate measurements were 0.99 for height and 0.98 for weight). Plasma was separated immediately and all fasting glucose samples were measured within $4 \mathrm{~h}$. Every tenth sample was measured twice (correlation coefficient of duplicate measurements was 0.98), at the same time, one reference sample, one quality control sample and one blind sample were measured before every thirtieth sample ${ }^{18}$. Blind serum samples provided by the US Center for Disease Control were analysed in our laboratory (China Center for Disease Control) seven times at regular intervals over the course of the analysis of the samples from the 2002 China National Nutrition and Health Survey; the relative difference ranged from $-7.02 \%$ to $1.60 \%$ for TAG and from $-1.05 \%$ to $4.21 \%$ for HDL-cholesterol ${ }^{18}$.

\section{Definition}

Metabolic syndrome was defined, using the criteria proposed by de Ferranti et $_{\text {al. }}{ }^{15}$, as three or more of the following variables and cut-off points: (1) fasting TAG $\geq 1.1 \mathrm{mmol} / \mathrm{l}(100 \mathrm{mg} / \mathrm{dl})$; (2) HDL-cholesterol boys $<1.2 \mathrm{mmol} / \mathrm{l} \quad(45 \mathrm{mg} / \mathrm{dl})$; girls $<1.3 \mathrm{mmol} / \mathrm{l}(50 \mathrm{mg} / \mathrm{dl})$; (3) fasting glucose $\geq 6.1 \mathrm{mmol} / \mathrm{l}$ $(110 \mathrm{mg} / \mathrm{dl})$; (4) waist circumference $>75$ th percentile for age and sex for US adolescents; (5) systolic blood pressure and/or diastolic blood pressure $>90$ th percentile for sex, age and height recommended by the National Heart, Lung, and Blood Institute (USA) ${ }^{19}$. The ATP III criteria ${ }^{2}$ were used for the definition of the adults (parents) metabolic syndrome. BMI was calculated as body weight divided by the square of height $\left(\mathrm{kg} / \mathrm{m}^{2}\right)$, in order to compare with US adolescents, the BMI status was classified by age-, sex- specific BMI standards for US adolescents $(<85$ th, 85 th -95 th and $\geq 95$ th percentile by age and sex $)^{20}$.

\section{Statistical analysis}

The prevalence of metabolic syndrome was estimated overall, by sex, by region (urban or rural), by BMI and stratified by the presence of parental metabolic syndrome. BMI was estimated using the US historical percentiles that were derived from the NHANES III survey: normal weight $<85$ th; at risk of overweight: 85th-95th; overweight: $\geq 95$ th percentile of US adolescents by age and $\operatorname{sex}^{20}$. Prevalence values were compared using $\chi^{2}$ tests. Sampling weights were applied to national estimates according to the data of the Fifth National Population Census ${ }^{21}$. All statistical analyses were done with SAS (8.2e for Windows; SAS Institute Inc. Cary, NC, USA), and the significance level was set at 0.05.

\section{Results}

Characteristics of adolescents and their parents are shown in Table 1. A total of 2761 adolescents (boys 1478; girls 1283)

Table 1. Characteristics of adolescents and their parents* (Mean values and standard deviations)

\begin{tabular}{|c|c|c|c|c|c|c|}
\hline \multirow[b]{3}{*}{$n$} & \multirow{2}{*}{\multicolumn{2}{|c|}{$\frac{\text { Adolescents }}{2761}$}} & \multirow{2}{*}{\multicolumn{2}{|c|}{$\begin{array}{c}\text { Mother } \\
2326\end{array}$}} & \multirow{2}{*}{\multicolumn{2}{|c|}{$\begin{array}{c}\text { Father } \\
2064\end{array}$}} \\
\hline & & & & & & \\
\hline & Mean & SD & Mean & SD & Mean & SD \\
\hline Age (years) & $17 \cdot 1$ & 1.5 & 42.7 & 4.9 & 44.9 & $5 \cdot 6$ \\
\hline Height (cm) & $162 \cdot 3$ & $8 \cdot 8$ & $155 \cdot 9$ & $6 \cdot 0$ & $166 \cdot 6$ & 6.4 \\
\hline Weight (kg) & 53.2 & $10 \cdot 2$ & $57 \cdot 3$ & $9 \cdot 7$ & 64.7 & $11 \cdot 2$ \\
\hline BMI $\left(\mathrm{kg} / \mathrm{m}^{2}\right)$ & $20 \cdot 1$ & 3.0 & 23.5 & 3.4 & 23.2 & $3 \cdot 3$ \\
\hline
\end{tabular}

${ }^{*}$ For details of subjects and procedures, see Subjects and methods. 
Table 2. Number of metabolic syndrome risk factors among Chinese adolescents aged 15-19 years, 2002CNNHS $(\%) \dagger$

\begin{tabular}{|c|c|c|c|c|c|}
\hline & \multirow[b]{2}{*}{ No. of subjects } & \multicolumn{4}{|c|}{ No. of risk factors } \\
\hline & & $\geq 1$ & $\geq 2$ & $\geq 3$ (MetS) & $\geq 4$ \\
\hline \multicolumn{6}{|l|}{ Adolescent characteristics } \\
\hline Total & 2761 & 68.5 & $23 \cdot 3$ & $3 \cdot 7$ & 0.6 \\
\hline \multicolumn{6}{|l|}{ Sex } \\
\hline Boy & 1478 & $65 \cdot 0$ & $23 \cdot 0$ & 3.4 & 0.6 \\
\hline Girl & 1283 & $72 \cdot 6$ & 23.9 & 4.0 & 0.5 \\
\hline \multicolumn{6}{|l|}{ Region } \\
\hline Urban & 833 & 60.5 & $19 \cdot 2$ & 4.2 & 1.5 \\
\hline Rural & 1928 & $72 \cdot 0$ & $25 \cdot 1$ & 3.5 & 0.1 \\
\hline \multicolumn{6}{|l|}{ BMI status, percentile } \\
\hline Normal ( $<85$ th $)$ & 2613 & $67 \cdot 0^{\star *}$ & $20 \cdot 6^{\star \star}$ & $2 \cdot 3^{* *}$ & 0.0 \\
\hline At risk (85th to $<95$ th) & 94 & 81.9 & $60 \cdot 6$ & 23.4 & 6.4 \\
\hline Overweight ( $\geq 95$ th) & 54 & $96 \cdot 3$ & $74 \cdot 1$ & $35 \cdot 2$ & 18.5 \\
\hline \multicolumn{6}{|l|}{ Parent characteristics } \\
\hline \multicolumn{6}{|l|}{ Mother's MetS status } \\
\hline No & 2218 & $67 \cdot 5^{\star \star}$ & $22 \cdot 5^{\star \star}$ & $3.3^{\star \star}$ & $0.5^{\star *}$ \\
\hline Yes & 108 & 81.5 & 37.0 & $11 \cdot 1$ & 3.7 \\
\hline \multicolumn{6}{|l|}{ Father's MetS status } \\
\hline No & 1920 & $67 \cdot 6$ & $22 \cdot 4^{\star \star}$ & $3 \cdot 3^{\star \star}$ & $0.5^{\star \star}$ \\
\hline Yes & 144 & $72 \cdot 9$ & $36 \cdot 1$ & $11 \cdot 8$ & 3.5 \\
\hline \multicolumn{6}{|l|}{ Parental MetS status } \\
\hline No (Both) & 1656 & $67 \cdot 1^{\star \star}$ & $22 \cdot 3^{\star \star}$ & $3 \cdot 0^{\star \star}$ & $0.4^{\star *}$ \\
\hline Yes (1 or both) & 205 & $76 \cdot 6$ & $34 \cdot 6$ & $10 \cdot 7$ & 3.4 \\
\hline \multicolumn{6}{|l|}{ Mother's educational level } \\
\hline Low (illiterate) & 255 & $67 \cdot 3$ & $23 \cdot 2$ & $2 \cdot 0$ & 0.0 \\
\hline Middle (Primary or Junior middle school) 1208 & 1208 & 69.9 & $24 \cdot 7$ & $4 \cdot 1$ & 0.5 \\
\hline High (Senior middle school or above) & 398 & $64 \cdot 2$ & 20.5 & 4.6 & 1.8 \\
\hline \multicolumn{6}{|l|}{ Family's economic level (Yuan/Year/per family member) } \\
\hline$<2000$ & 837 & $71 \cdot 8^{\star *}$ & $25 \cdot 6$ & $3.0^{*}$ & $0.4^{* *}$ \\
\hline $2000-10000$ & 860 & $66 \cdot 3$ & $22 \cdot 6$ & 4.3 & 0.6 \\
\hline$\geq 10000$ & 140 & $60 \cdot 0$ & $17 \cdot 9$ & $7 \cdot 1$ & 3.6 \\
\hline
\end{tabular}

CNNHS, China National Nutrition and Health Survey, MetS, metabolic syndrome, with three or more risk factors.

$\chi^{2}$-test of prevalence of metabolic syndrome risk factors between subgroups: ${ }^{\star} P<0.05 ;{ }^{\star \star} P<0.01$.

†For details of subjects and procedures, see Subjects and methods.

aged $17 \cdot 1$ (SD 1.5) (15-19) years participated in the investigations. A total of 2326 adolescents' mothers aged 42.7 (SD 4.9) years and 2064 adolescents' fathers aged 44.9 (SD 5.6) years finished all measurements for metabolic syndrome; among them, there were 1861 couples.

Prevalence of metabolic syndrome is shown in Table 2. The overall prevalence of metabolic syndrome in Chinese adolescents aged 15-19 years was $3.7 \%$. Based on population weighting, we have estimated that more than three million Chinese adolescents have metabolic syndrome. Metabolic syndrome was present in $35.2 \%$ of overweight adolescents (BMI $\geq 95$ th percentile) compared with $23.4 \%$ of at-risk adolescents (BMI 85th to $<95$ th percentile) and $2.3 \%$ of those with a BMI below the 85 percentile $(P<0.01)$. The prevalence of metabolic syndrome by sex and region is shown in Fig. 1. Urban boys had the highest rate at $5.8 \%$, whereas their rural counterparts $(2.9 \%)$ had the lowest rate $(P<0.01)$. Urban girls had comparable prevalence as their rural counterparts $(3.5 \%$ v. $3.7 \%)$.

Adolescents having parent(s) with metabolic syndrome had a higher rate of metabolic syndrome than their counterparts $(10.7 \%$ v. $3.0 \%, P<0.01$; Table 2). The prevalence of metabolic syndrome by adolescents' BMI status and parental metabolic syndrome status is shown in Fig. 2. Among normal weight adolescents, metabolic syndrome prevalence was low whether they had parents with $(5.1 \%)$ or without $(2.1 \%)$ metabolic syndrome. Once they became overweight or were at risk of overweight, the prevalence increased dramatically, especially if their parent(s) had metabolic syndrome. More than $40 \%(46.4 \%)$ of adolescents who had BMI $\geq 85$ th percentile and parent(s) with metabolic syndrome met the criteria of metabolic syndrome.

The proportion of subjects with one or more metabolic abnormalities is also shown in Table $1,96.3 \%$ overweight

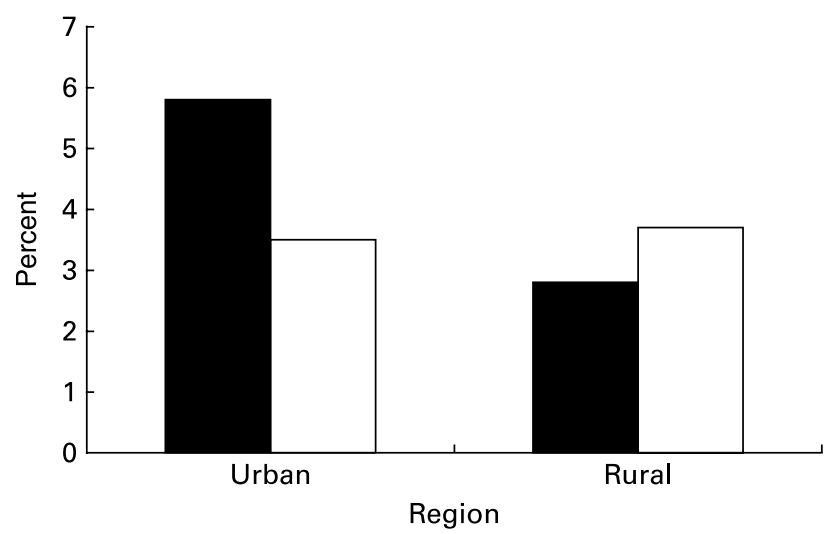

Fig. 1. Prevalence of the metabolic syndrome by sex (boys $\mathbf{\square}$; girls $\square$ ) and region. For details of subjects and procedures, see Subjects and methods. 


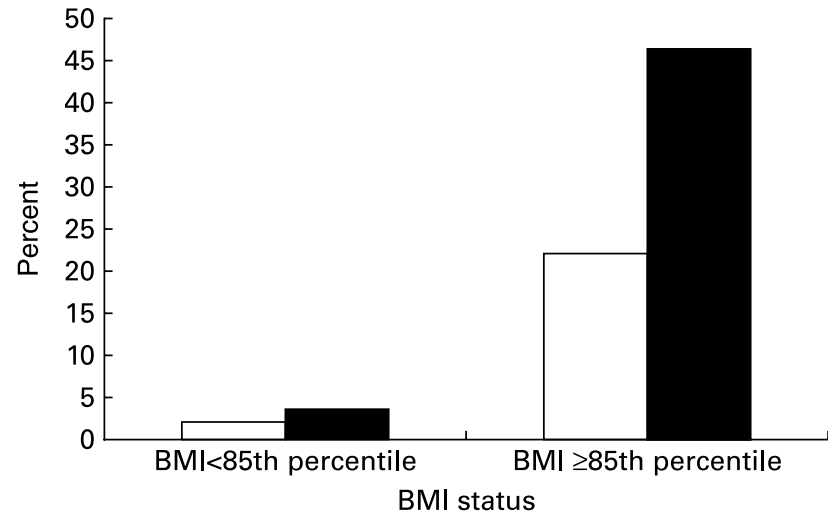

Fig. 2. Prevalence of adolescent's metabolic syndrome by their BMI status and parental metabolic syndrome (MetS) status ( $\square$, no parents with MetS; one or more parents with MetS). For details of subjects and procedures, see Subjects and methods.

adolescents had at least one and $74.1 \%$ had at least two abnormalities of metabolic syndrome. The distribution of each metabolic abnormality is shown in Table 3. Overall, low HDL-cholesterol levels were the most common, whereas high fasting glucose levels and abdominal obesity were the least common abnormality. Central obesity, high fasting glucose, high TAG level and hypertension all significantly worsened with increasing body weight status.

The prevalence of metabolic syndrome of children with a high family income was significantly higher than their counterparts whose family incomes were low or intermediate. No significant association was found between mother's educational level and the child's metabolic syndrome (Table 2). Family income status was also positively associated with the risk of having four metabolic abnormalities, but the children from poor families were at a significantly higher risk of having at least one metabolic abnormality. Family income status was also positively related to the prevalence of abdominal obesity and negatively related to HDL-cholesterol level. The prevalence of low HDL-cholesterol level among children whose mother's educational level was low $(49.6 \%)$ or high $(45.8 \%)$ was both lower than those whose mother's educational level was medium $(54.2 \%)$ (Table 3).

\section{Discussion}

This is the first study examining the prevalence and distribution of metabolic syndrome among 15- to 19-year-old Chinese adolescents using a national representative sample. Compared with

Table 3. Prevalence of individual metabolic syndrome risk factors among Chinese adolescents aged 15 to 19 years, $2002 \mathrm{CNNHS}$ (\%) $\dagger$

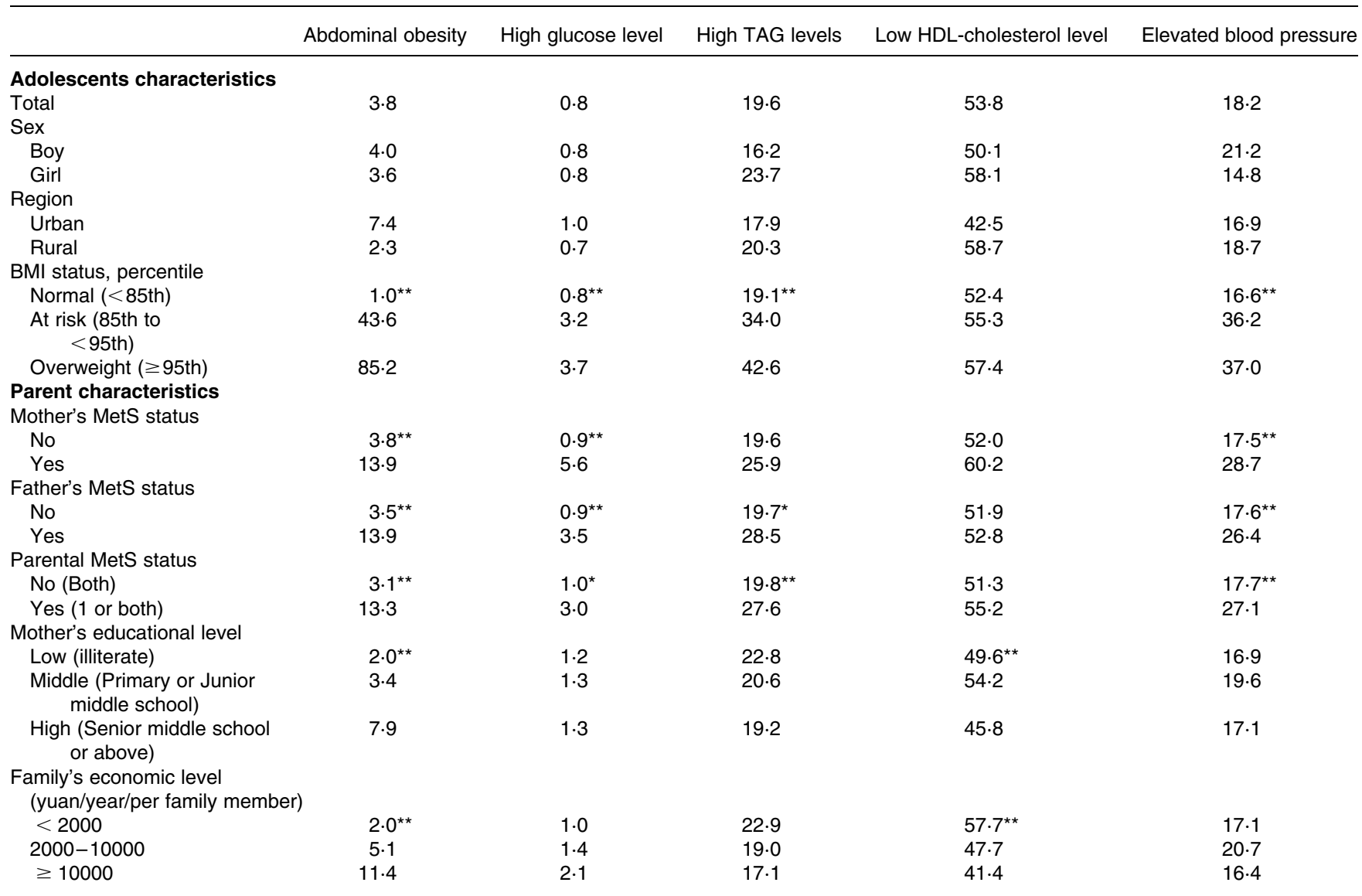

CNNHS: China National Nutrition and Health Survey; MetS, Metabolic syndrome, with three or more risk factors.

$\chi^{2}$-test of prevalence of individual metabolic syndrome between subgroups: ${ }^{\star} P<0.05,{ }^{\star \star} P<0.01$.

†For details of subjects and procedures, see Subjects and methods. 
their US counterparts, the prevalence of metabolic syndrome is still low in China (about $10 \%$ in the USA v. $3.7 \%$ in China) ${ }^{15}$. The prevalence of metabolic syndrome among overweight adolescents is quite similar in China and in the USA $(27.7 \% v$. $31.2 \%$ ). Overweight adolescents who had one, two, three and four items of the metabolic abnormalities are also comparable between Chinese $(75.9 \%, 51.9 \%, 20.4 \%$ and $5.6 \%)$ and US adolescents $(88.5 \%, 56.0 \%, 28.7 \%$ and $5.8 \%$ ) (both applying the criteria developed by Cook et al. $)^{14}$.

Comparing the different individual metabolic abnormalities between Chinese and US adolescents ${ }^{14,15}$, the prevalence of abdominal obesity and high TAG levels was lower, while the prevalence of low HDL-cholesterol level and elevated blood pressure was higher among Chinese than US adolescents. The differences may be caused by genetic factors, dietary habits, physical activity patterns or other lifestyle differences that need further research. High levels of HDL-cholesterol have previously been reported in some Chinese populations ${ }^{22}$, more recent data, however, suggested that the lipid profile of Asian populations is changing with a trend toward decreased HDL-cholesterol and increased total cholesterol and LDL-cholesterol, possibly as a result of changing lifestyles $^{23,24}$. Serum lipid concentrations of various Chinese population samples are now closer to that of Western populations ${ }^{25,26}$. In order to compare with the US adolescents, we used the old cut-point for high glucose level of $110 \mathrm{mg} /$ dl. When the new cut-point of $100 \mathrm{mg} / \mathrm{dl}$ was applied, $2.8 \%$ of Chinese adolescents had a high glucose level.

One limitation of the present study is that the estimation of metabolic syndrome is based on a proposed definition for US adolescents using the historical cut-points from the NHANES III due to the lack of a metabolic syndrome definition for Chinese adolescents. Whether the US criteria are applicable for Chinese adolescents is still questionable. As previous studies found a higher body fat percentage at the same BMI among Asian adults, specific overweight (BMI ranging from $24.0 \mathrm{~kg} / \mathrm{m}^{2}$ to $27.9 \mathrm{~kg} / \mathrm{m}^{2}$ ) and obesity (BMI equal or above $28 \mathrm{~kg} / \mathrm{m}^{2}$ ) definitions were then developed ${ }^{27-29}$. Using the US upper limits for waist circumference may have underestimated the prevalence, while using the US lower limit for HDL-cholesterol level may have overestimated the prevalence, considering the generally lower adult weight and waist circumference of Chinese compared with US adults. Another limitation of the present study is that we compared the Chinese adolescents aged 15-19 years with US adolescents aged 12-19 years. As similar results were found for older and younger adolescents in the USA ${ }^{14,15}$, our comparison may still be valid.

Strengths of the study were the national representativeness and the high quality control of physical examination and laboratory analysis ${ }^{18}$. High reproducibility was observed in our duplicate measurements; moreover, there is good agreement between Chinese and American laboratory measurements in TAG and HDL-cholesterol. Evaluating parental history of metabolic syndrome was also a strength of the present study.

In conclusion, the prevalence of metabolic syndrome is lower among Chinese than US adolescents. But among overweight subjects, the prevalence of metabolic syndrome is comparable. It is estimated that more than three million Chinese adolescents aged 15 to 19 years have metabolic syndrome and $40 \%$ of them have elevated body weight. Of the adolescents having parents with metabolic syndrome, once they are overweight or at risk of overweight, their risk of metabolic syndrome would be much higher. The present findings highlight the need for effective childhood obesity prevention strategies and actions in China, especially among the adolescents having parents with metabolic syndrome.

\section{Acknowledgements}

We thank all the team members and all participants from thirty-one provinces of China. Special thanks are for Professor Evert G. Schouten for his contribution to this paper. None of the authors had any personal or financial conflicts of interest. The '2002 China National Nutrition and Health Survey' was supported by Ministry of Health and Ministry of Science and Technology, China (2001DEA30035, 2003DIA6N008). UNICEF, WHO, Unilever China and Danone Nutrition Institute China.

\section{References}

1. Kahn R, Buse J, Ferrannini E \& Stern M (2005) American Diabetes Association; European Association for the Study of Diabetes: The metabolic syndrome: time for a critical appraisal: joint statement from the American Diabetes Association and the European Association for the Study of Diabetes. Diabetes Care 28, 2289-2304.

2. Expert Panel on Detection, Evaluation and Treatment of High Blood Cholesterol in Adults (Adults Treatment Panel III) (2001) Executive Summary of The Third Report of The National Cholesterol Education Program (NCEP) Expert Panel on Detection, Evaluation, And Treatment of High Blood Cholesterol In Adults (Adult Treatment Panel III). JAMA 285, 2486-2497.

3. Expert Panel on Detection, Evaluation, and Treatment of High Blood Cholesterol in Adults (2002) Third Report of the National Cholesterol Education Program (NCEP) Expert Panel on Detection, Evaluation, and Treatment of High Blood Cholesterol in Adults (Adult Treatment Panel III) final report. Circulation 106, 3143-3421.

4. Alberti KG, Zimmet P \& Shaw J (2005) IDF Epidemiology Task Force Consensus Group: The metabolic syndrome - a new worldwide definition. Lancet 366, 1059-1062.

5. Balkau B, Charles MA, Drivsholm T, et al. (2002) European Group For The Study Of Insulin Resistance (EGIR): Frequency of the WHO metabolic syndrome in European cohorts, and an alternative definition of an insulin resistance syndrome. Diabetes Metab 28, 364-376.

6. Einhorn D, Reaven GM, Cobin RH, et al. (2003) American College of Endocrinology position statement on the insulin resistance syndrome. Endocr Pract 9, 237-252.

7. World Health Organization (1999) Definition, Diagnosis, and Classification of Diabetes Mellitus and its Complications: Report of a WHO Consultation. Geneva: WHO.

8. Chu NF, Rimm EB, Wang DJ, Liou HS \& Shieh SM (1998) Clustering of cardiovascular disease risk factors among obese schoolchildren: the Taipei Children Heart Study. Am J Clin Nutr 67, 1141-1146.

9. Csabi G, Torok K, Jeges S \& Molnar D (2000) Presence of metabolic cardiovascular syndrome in obese children. Eur $J$ Pediatr 159, 91-94. 
10. Vanhala M, Vanhala P, Kumpusalo E, Halonen P \& Takala J (1998) Relation between obesity from childhood to adulthood and the metabolic syndrome: population based study. BMJ 317, 319 .

11. Vanhala MJ, Vanhala PT, Keinanen-Kiukaanniemi SM, Kumpusalo EA \& Takala JK (1999) Relative weight gain and obesity as a child predict metabolic syndrome as an adult. Int J Obes Relat Metab Disord 23, 656-659.

12. Weiss R, Dziura J, Burgert TS, et al. (2004) Obesity and the metabolic syndrome in children and adolescents. $N$ Engl $J$ Med 350, 2362-2374.

13. Yoshinaga M, Tanaka S, Shimago A, Sameshima K, Nishi J, Nomura Y, Kawano Y, Hashiguchi J, Ichiki T \& Shimizu S (2005) Metabolic syndrome in overweight and obese Japanese children. Obes Res 13, 1135-1140.

14. Cook S, Weitzman M, Auinger P, Nguyen M \& Dietz WH (2003) Prevalence of a metabolic syndrome phenotype in adolescents: findings from the third National Health and Nutrition Examination Survey, 1988-1994. Arch Pediatr Adolesc Med 157, 821-827.

15. de Ferranti SD, Gauvreau K, Ludwig DS, Neufeld EJ, Newburger JW \& Rifai N (2004) Prevalence of the metabolic syndrome in American adolescents: findings from the Third National Health and Nutrition Examination Survey. Circulation 110, 2494-2497.

16. Li Y, Chen C, Kong L, Yang X, Zhai F, Zhang J \& Ma G (2005) Child obesity in China: prevalence, determinants and its relationship to cardiovascular risk factors. In Abstracts 18th International Congress of Nutrition. Durban, South Africa: Medical and Scientific Publishers, 19-23 September, Nutrition Safari for Innovative solutions.

17. Li Y, Zhai F, Yang X, Schouten EG, Hu X, He Y, Luan D \& Ma $G$ (2007) Determinants of childhood overweight and obesity in China. Br J Nutr 97, 210-215.

18. Wang L (2005) Report of China Nationwide Nutrition and Health Survey 2002 (1): Summary Report, pp. 18-45. Beijing: People's Medical Publishing House.

19. National High Blood Pressure Education Program Working Group on Hypertension Control in Children and Adolescents (1996) Update on the 1987 Task Force Report on High Blood Pressure in Children and Adolescents National High Blood
Pressure Education Program. A working group report. Pediatrics 98, 649-658.

20. Centers for Disease Control (2000) CDC growth charts: united states (Database online). Available from http://www.cdc.gov/ nchs/data/nhanes/growthcharts/bmiage.txt (accessed 20 July 2005).

21. National Bureau of Statistics of China (2000) China Statistical Yearbook 2000. Beijing: China Statistics Press.

22. Kesteloot H, Huang DX, Yang XS, Yang XS, Claes J, Rosseneu M, Geboers J \& Joossens JV (1985) Serum lipids in the People's Republic of China. Comparison of Western and Eastern populations. Arteriosclerosis 5, 427-433.

23. Chen Z, Peto R, Collins R, MacMahon S, Lu J \& Li W (1991) Serum cholesterol concentration and coronary heart disease in population with low cholesterol concentrations. BMJ 303, 276-282.

24. Davis CE, Williams DH, Oganov RG, Tao SC, Rywik SL, Stein Y \& Little JA (1996) Sex difference in high density lipoprotein cholesterol in six countries. Am $J$ Epidemiol 143, $1100-1106$.

25. Campbell TC, Parpia B \& Chen J (1998) Diet, lifestyle, and the etiology of coronary artery disease: the Cornell China study. Am $J$ Cardiol 82, 18T-21T.

26. McGladdery SH, Pimstone SN, Clee SM, Bowden JF, Hayden MR \& Frohlich JJ (2001) Common mutations in the lipoprotein lipase gene (LPL): effects on HDL-cholesterol levels in a Chinese Canadian population. Atherosclerosis 156, 401-407.

27. Cooperative Meta-analysis Group of China Obesity Task Force (2002) Predictive value of body mass index and waist circumference to risk factors of related diseases in Chinese adults population. Zhong Hua Liu Xing Bing Xиe Za Zhi 23, 5-10.

28. Group of China Obesity Task Force (2004) Body mass index reference norm for screening overweight and obesity in Chinese children and adolescents. Zhong Hua Liu Xing Bing Xue Za Zhi 25, 97-102.

29. International Diabetes Institute (2002) The Asia-Pacific Perspective: Redefining Obesity and its Treatment. WHO Regional Office for the Western Pacific with the International Association for the Study of Obesity and the International Obesity Task Force. Sydney: Health Communications Australia. 